\title{
THE EVOLUTION OF THE JOURNAL OF APPLIED ORAL SCIENCE: A BIBLIOMETRIC ANALYSIS
}

\author{
Valéria Cristina Trindade FERRAZ ${ }^{1}$, José Roberto Plácido AMADEI² ${ }^{2}$ Carlos Ferreira SANTOS ${ }^{3}$
}

1- Librarian, Technical Supervisor at the Documentation and Publishing Service of the Library and Documentation Service of the Bauru School of Dentistry, University of São Paulo, Bauru, SP, Brazil.

2- Librarian at the Documentation and Publishing Service of the Library and Documentation Service of the Bauru School of Dentistry, University of São Paulo, Bauru, SP, Brazil.

3-DDS, MSc, PhD, Associate Professor, Editor-in-Chief, Jounal Applied of Oral Science, Department of Biological Sciences, Bauru School of Dentistry, University of São Paulo, Bauru SP, Brazil.

Corresponding address: Valéria Cristina Trindade Ferraz - Serviço de Documentação e Divulgação do Serviço de Biblioteca e Documentação da Faculdade de Odontologia de Bauru, Universidade de São Paulo - Alameda Octávio Pinheiro Brisolla, 9-75 - 17012-901 Bauru, SP, Brasil. Phone: +55 14 3235-8373 - Fax: +55 1432358330 - e-mail: jaos@usp.br

Received: May 5, 2008 - Accepted: August 27, 2008

\begin{abstract}
7 2005 and 2007 , articles published in the JAOS in the time span established for this survey were analyzed retrospectively and a discussion was undertaken on the data referring to the main bibliometric indexes of production, authorship, bibliographic sources of the published articles, and the most frequently cited scientific journals in the main dental research fields. A total of 247 papers authored and coauthored by 1,139 contributors were reviewed, most of them being original research articles. The number of authors per article was 4.61 on the average. Regarding the geographic distribution, the authors represented almost all of the Brazilian States. Most published articles belonged to the following dental research fields: Endodontics, Restorative Dentistry, Dental Materials and Prosthodontics. The ranking of the most frequently cited scientific journals included the most reputable publications in these dental research fields. In conclusion, between 2005 and 2007, the JAOS either maintained or improved considerably its bibliometric indexes. The analysis of the data retrieved in this study allowed evaluating the journal's current management strategies, and identifying important issues that will help outlining the future directions for the internationalization of this journal.
\end{abstract}

Key words: Bibliometrics. Dentistry. Scientific journal. Journal of Applied Oral Science.

\section{INTRODUCTION}

Publishing the outcomes of research studies conducted by its professors and graduate students has always been a primary concern of the Bauru School of Dentistry (FOB) of the University of São Paulo (USP). In fact, the history of FOB's scientific journal is practically coincident with the foundation of this institution.

In 1968, FOB launched its first scientific journal, named Estomatologia \& Cultura, which was intended to publish the results of laboratorial and clinical investigations performed by FOB's faculty and students exclusively. Estomatologia \& Cultura was published up to 1986, with an interruption between 1978 and 1981.

In 1987, the three Dental Schools of the University of São Paulo, namely FOB, FOUSP (campus of São Paulo) and FORP (campus of Ribeirão Preto) felt the need to join their efforts in the creation of a single journal for publication of the scientific production of these three institutions. Therefore, Estomatologia \& Cultura (published by FOB), the Revista da Faculdade de Odontologia de Ribeirão Preto (published by FORP) and the Revista da Faculdade de Odontologia da Universidade de São Paulo (published by FOUSP), were merged into a single publication under the name Revista de Odontologia da Universidade de São Paulo.

Nevertheless, the remarkable improvement of FOB's graduate programs over the years increased considerably the development of dissertations and theses, leading the institutional Research Committee to consider the need of creating a new scientific journal that could assimilate the local scientific production. In order to fulfill this demand, the Revista da Faculdade de Odontologia de Bauru was created in 1993. Since its foundation, the Revista da Faculdade de Odontologia de Bauru, now renamed as the Journal of Applied Oral Science (JAOS), had as Editors-inChief several professors from FOB's faculty, who had a great 
participation and played important roles in the internationalization of this journal.

Listed below are the main changes and strategies implemented by the last Editors-in-Chief of the JAOS.

2001-2004: in this period, the Revista da Faculdade de Odontologia de Bauru was under the scientific coordination of Dr. José Mauro Granjeiro, DDS, MSc, $\mathrm{PhD}$, and the main changes were the following:

- In 2003, the Revista da Faculdade de Odontologia de Bauru was renamed as the Journal of Applied Oral Science, with publication of English-language articles only;

- The editorial board was reformulated in order to widen the geographic distribution of the ad hoc reviewers;

- Important changes were made in the peer review guidelines. A structured form named "Criteria and guidelines for peer review" was developed and provided to the reviewers in order to have the articles reviewed in a more diligent and standardized manner;

- The JAOS was indexed in the SciELO (Scientific Electronic Library Online) electronic database, which is an online library consisting of Brazilian scientific journals that have met specific inclusion criteria and have been selected to integrate its collection. With this achievement, the JAOS was rated by the Coordination of Higher Education and Graduate Training (CAPES) as a National QUALIS A journal.

- In 2004, the "Uniform Requirements for Manuscripts Submitted to Journals", which is a set of guidelines accepted worldwide for manuscript presentation and reference format, were adopted by the JAOS. These new directions optimized the contact with the authors and facilitated the submission of articles authored by foreign contributors.

- 2005-2006: Dr. Ricardo Marins de Carvalho, DDS, $\mathrm{PhD}$, took over as the Editor-in-Chief of the JAOS, and widened the participation of foreign reviewers in the journal.

- 2006-present date: Starting as the new Editor-in-Chief of the JAOS in August, Dr. Carlos Ferreira dos Santos, DDS, $\mathrm{MSc}, \mathrm{PhD}$, has focused his administration mainly on journal indexation in international electronic databases. In the same year, the JAOS was indexed in SCOPUS, the world's largest abstract and citation multidisciplinary database of peerreviewed literature and web sources, comprehending the fields of Life Sciences, Health Sciences (including all publications indexed in Medline/PubMed electronic database), Physical and Social Sciences;

- In 2007, several changes were implemented in the journal's editorial management. The most important was the implementation of an online submission and editorial system, which increased the participation of foreign peerreviewers and contributors. The use of an online submission and peer-review site enables immediate distribution of manuscripts and consequentially speeds up the review process. It also allows authors to track the status of their own manuscripts. Still in 2007, the clinical trials published in the JAOS were indexed in the Cochrane Library, an electronic database consisting of updated medical information sources based on evidence and systematic reviews. As a direct result of these efforts, the Editor-in-
Chief was invited to submit the JAOS for evaluation by one of the most important international scientific research databases, The Science Citation Index Expanded (SCIE) published by Thomson Scientific. The SCIE provides access to current and retrospective bibliographic information, abstracts, and cited references found in approximately 5,900 of the world's leading scholarly science and technical journals covering more than 150 disciplines.

- Starting with the issues published in 2007, the JAOS was integrated to the SCIE collection. This achievement was of paramount importance because the indexation in SCIE database qualified the JAOS as an international publication. Very few dental journals are indexed in SCIE database, which demonstrates its highly selective inclusion criteria and procedures for acceptance in the collection, which is available through Web of Science ${ }^{\circledR}$ and the online version SciSearch ${ }^{\circledR}$.

It is known that the analysis of the subjects published in the main journals of a certain field of knowledge is a manner to learn about its scientific profile. Therefore, tracking and reviewing articles published in the JAOS aimed to assess some important aspects of its scientific production, such as the quality of continued education, which, for great part of the researchers is achieved by scientific reading; the increase and use of knowledge in a particular area; the increase in the efficiency of mechanisms for distribution of limited resources; and the encouragement of research funding ${ }^{2}$.

In science and technology, the indicators play an important role in outlining the course of such activities in a certain region or country. New techniques for data collection and analysis are ever more developed, and might be used as bases for the construction of reliable data. Regarding scientific journals, the bibliometric indicators are useful for assessing the journal's internal affairs, its relative position with respect to the dispute for scientific publication, and the basis for strategic editorial policies ${ }^{1}$.

The changes observed in the recent years in the quality of the articles published in the JAOS resulted fundamentally from the improvement of the journal's peer-review system allied to the requirements of the Brazilian funding agencies with respect to the assessment of the scientific production of the graduate courses offered by higher education institutions.

This new scenario produced a positive response, resulting in the submission of articles that meet the standards of quality as well as in the establishment of more selective criteria and assessment strategies, which apply both for authors and for reviewers. Ultimately, this approach provided the required support and balance for the analysis of articles in the different fields of dental research. Therefore, a bibliometric analysis of the articles published in the JAOS between 2005 and 2007 was undertaken to characterize the scientific outcomes published in the journal in this period of great transformations $\mathrm{s}^{3-5}$. 


\section{METHODOLOGY}

The universe sample comprehended the last three volumes of JAOS, referring to the years 2005, 2006 and 2007. This time span was selected for being the one in which most changes were implemented in the JAOS structure and editorial policies. A total of 247 articles distributed in 17 issues were reviewed ${ }^{3-5}$.

The following data were retrieved from all articles published within the studied period and entered in Microsoft Excel ${ }^{\circledR}$ worksheets for further analysis: year, volume and issue of publication; type of paper (original research article, literature review article or case report); dental research field; references cited per paper, including the journal's title and the year of publication; author's geographic origin (country and state); number of manuscripts submitted for publication, percentage of rejected manuscripts and number of articles published per year (2005, 2006 and 2007). Details referring to some of the collected data are presented below:

\section{Type of Paper}

JAOS accepts for publication original research articles, literature review articles and case reports upon Editor's invitation. Pincus, et al. ${ }^{6}$ (1993) classification was used to define the types of article according to the following definitions:

- Original research article: manuscript presenting original data, systematically collected and with a clearly defined methodology;

- Literature review: review of previously published articles, including a synthetic presentation of ideas and outcomes, not having the authors as the primary source of data and information;

- Case report: description of up to 10 reports of clinical cases, not containing statistical summary.

\section{Dental Research Fields}

The papers were classified in different fields of dental research and correlated areas, as follows: Anatomy, Biochemistry, Dental Implants, Dental Materials, Dental Occlusion, Prosthodontics, Restorative Dentistry, Endodontics, Forensic Dentistry, Microbiology, Morphology, Orthodontics, Pathology, Pediatric Dentistry, Periodontics, Physiology, Preventive and Community Dentistry, Radiology, Speech Pathology and Audiology and Surgery.

\section{Criteria Adopted for the Analysis of the Cited References}

Only references of national and international scientific journals were considered in the analysis. Other types of references sources, such as books, chapter(s) of a book, legal references, dissertations and theses, internet-based information, and URLs, were classified as "other", i.e., bibliographic material other than journal papers.

For each dental research field and correlated area, all journals cited as references in the articles published in the JAOS (2005-2007) were recorded, and a top-10 ranking was established with the 10 most frequently cited journals per year in the four research fields to which most articles pertained (Endodontics, Restorative Dentistry, Dental Materials and Prosthodontics).

\section{Number of Manuscripts Submitted For Publication and Percentage of Rejection}

The analysis of these data provided information about the author's response to the adoption of more selective criteria with respect to the fulfillment of the technical normalization requirements; the quality of the article's scientific content; and the adequacy of the manuscripts to the journal's scope.

\section{RESULTS AND DISCUSSION}

Number of Submitted Manuscripts and Percentage of Rejected Manuscripts between 2005 and 2007

Table 1 presents the total number of manuscripts submitted to the JAOS between 2005 and 2007. The average of submissions and rejections per year was 154 and 70 manuscripts, respectively. The average of rejected

TABLE 1- Submitted and rejected manuscripts between 2005 and 2007

\begin{tabular}{lccc}
\hline Year & $\begin{array}{c}\text { Submitted } \\
\text { manuscripts }\end{array}$ & $\begin{array}{c}\text { Rejected } \\
\text { manuscripts }\end{array}$ & $\%$ \\
\hline 2005 & 156 & 70 & 44.87 \\
2006 & 160 & 83 & 51.87 \\
2007 & 148 & 58 & 39.18 \\
Average & 154 & 70 & 45.30 \\
\hline
\end{tabular}

TABLE 2- Number of issues, articles and types of published papers between 2005 and 2007

\begin{tabular}{lrrrr}
\hline & $\mathbf{2 0 0 5}$ & $\mathbf{2 0 0 6}$ & $\mathbf{2 0 0 7}$ & Total \\
\hline Number of issues & 4 & 7 & 6 & 17 \\
Number of articles & 78 & 79 & 90 & 247 \\
Literature review articles & 4 & 0 & 2 & 6 \\
Case Report & 1 & 1 & 1 & 3 \\
Original research articles & 73 & 78 & 87 & 238 \\
\hline
\end{tabular}


manuscripts per year increased from 45 to $52 \%$ between 2005 and 2006. In 2007, 39\% of the submitted manuscripts were not accepted.

Table 2 presents the main data referring to the number of issues, number of articles and types of papers published in the JAOS between 2005 and 2007. In this period 247 papers, were published and distributed among 17 issues. As the main scope of the journal is the publication of original research articles, this was by far the most common type of paper published in the last 3 years $(n=238)$, followed by literature review articles $(n=6)$ and case reports $(n=3)$.

\section{Authorship and Geographic Distribution of Authors}

Although the number of authors who had articles published in the JAOS increased considerably from 2005 to 2006 , the number of articles per volume in this period was the same. There was also an increase in the number of authors from 2006 to 2007, but there were 11 more articles in the 2007 volume (Table 2).

It should be mentioned the small number of authors from FOB, which publishes the journal, in all volumes evaluated in this study, which indicates the non-endogenous nature of the JAOS. In the last 3 years, the percentage of members of FOB's faculty and students who authored or coauthored manuscripts published in the JAOS was $24.31 \%$. The maximum allowed by electronic databases like BIREME SciELO is $40 \%$ per issue. This percentage has decreased considerably every year concomitantly with the increase of the participation of contributors from other national and even international institutions. The large number of authors from other institutions is due to the greater visibility of the journal after its indexation in important electronic literature databases.

The analysis of the geographic origin of the authors gives important information regarding the visibility of the journal in the different research segments and institutions both in Brazil and abroad. Until 2002, before the indexation of the

TABLE 3- Authorship and endogen index of the papers published in JAOS between 2005 and 2007

\begin{tabular}{lllll}
\hline & $\mathbf{2 0 0 5}$ & $\mathbf{2 0 0 6}$ & $\mathbf{2 0 0 7}$ & Total \\
\hline Total number of authors & 339 & 383 & 417 & 1139 \\
Mean number of authors/article & 4.34 & 4.84 & 4.63 & 4.61 \\
Authors from FOB & 97 & 81 & 99 & 277 \\
Endogen index & $28.61 \%$ & $21.14 \%$ & $23.74 \%$ & $24.32 \%$ \\
\hline
\end{tabular}

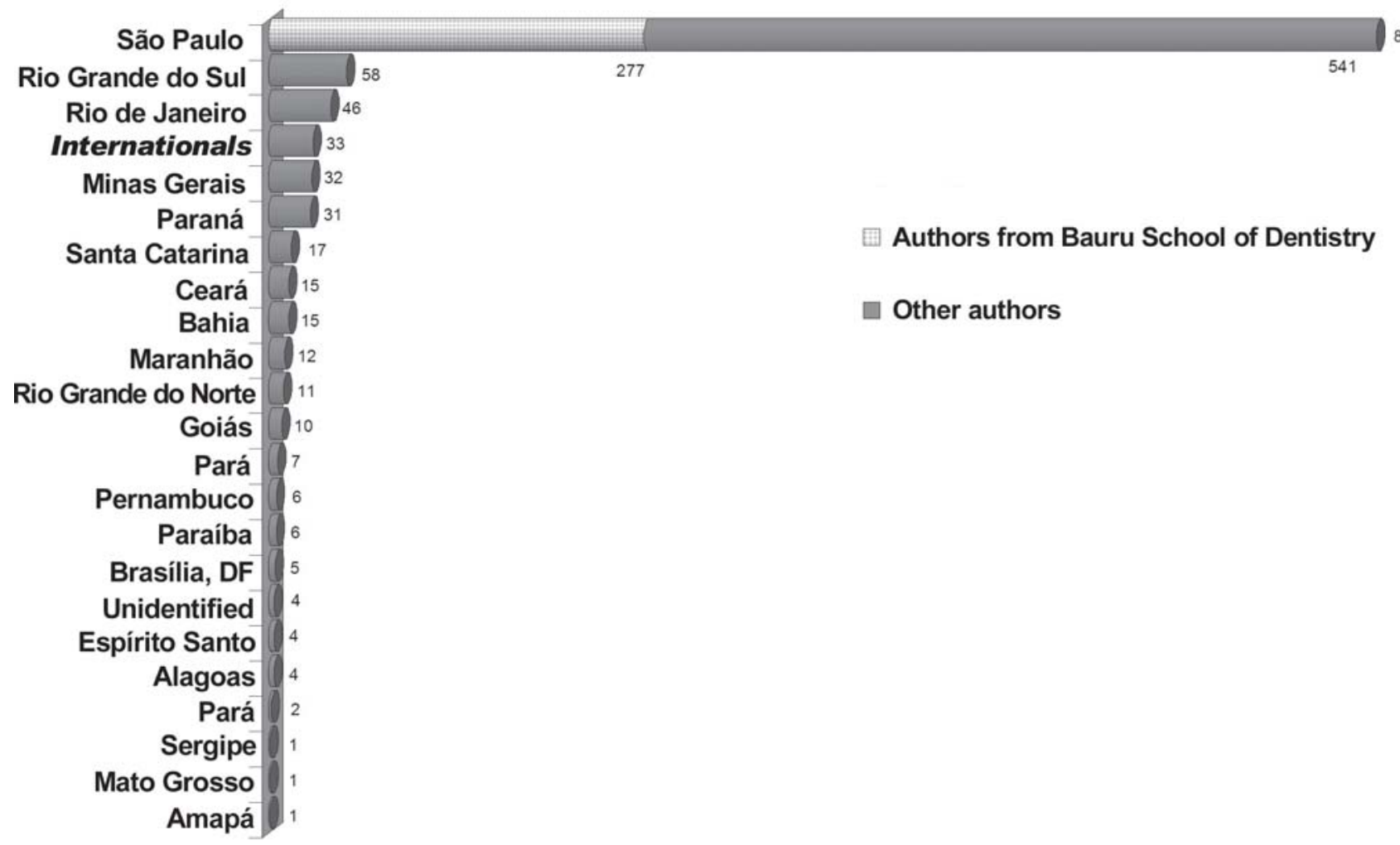

FIGURE 1- Geographic distribution of the authors who had articles published in the JAOS between 2005 and 2007 (Brazilian States and other countries) 
JAOS in the SciELO database, most articles submitted for publication were from local authors among whom the journal had greater recognition. After integration of the JAOS to the SciELO collection, there was a considerable increase in the number of contributors from other Brazilian States and foreign countries. Figure 1 illustrates the geographic distribution of the authors and coauthors of articles published in the JAOS between 2005 and 2007.
Due to its large number of dental schools, great part of them with a vast research expertise, the São Paulo State is responsible for most part of the production published in the JAOS, accounting to over $70 \%$ of the authors. Although the participation of other states still corresponds to considerably a smaller percentage of submissions, almost all Brazilian States are represented in the JAOS authorships. Contributors from 20 States plus the Federal District have authored or

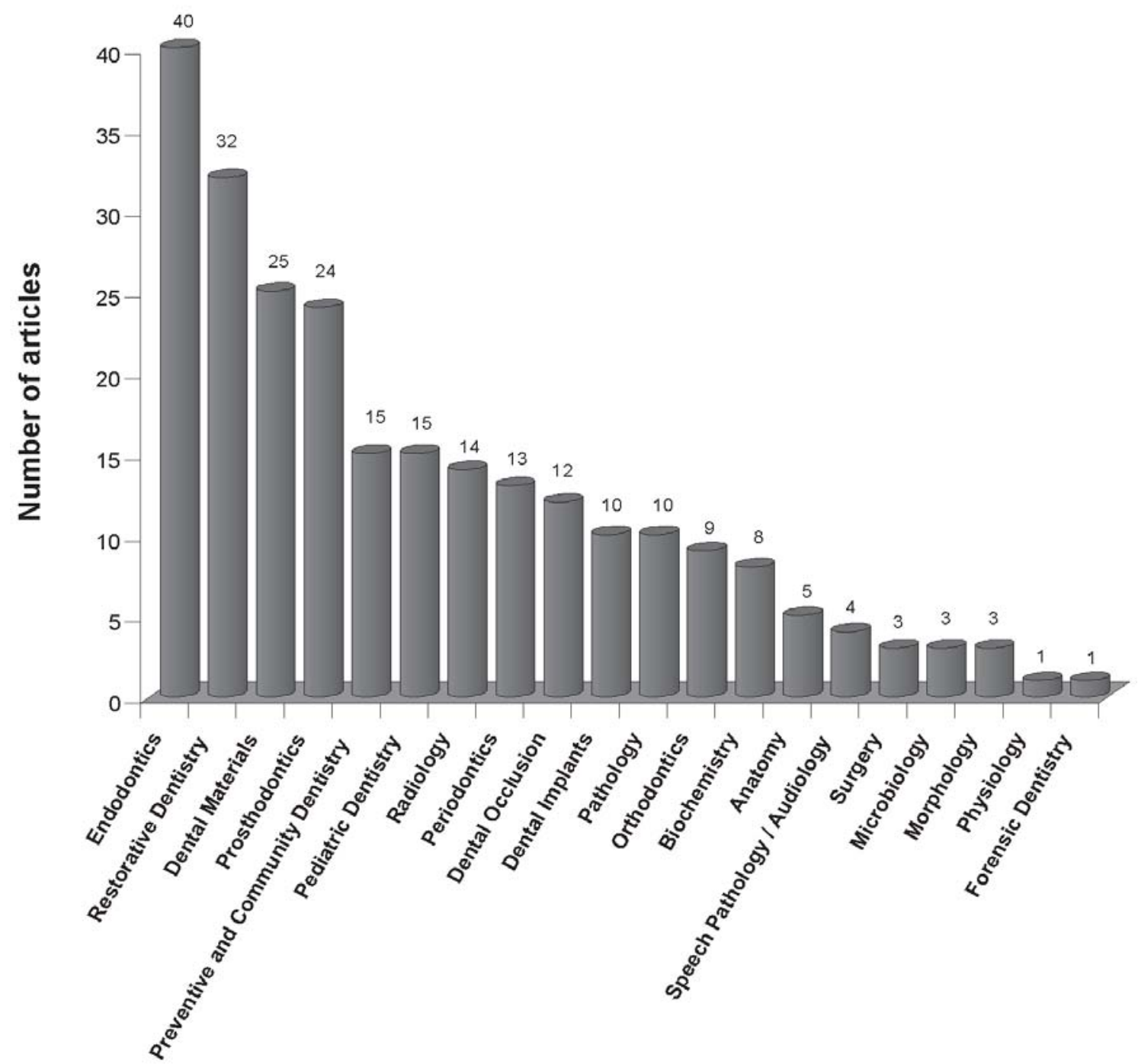

FIGURE 2- Number of articles published in the JAOS in each dental research field between 2005 and 2007

TABLE 4- Characteristics of the references cited in articles published in the JAOS between 2005 and 2007

\begin{tabular}{lcccc}
\hline & $\begin{array}{c}\text { Total number } \\
\text { of references }\end{array}$ & $\begin{array}{c}\text { Mean of references } \\
\text { per article }\end{array}$ & $\begin{array}{c}\text { Scientific journals } \\
\text { as source (\%) }\end{array}$ & Other sources* (\%) \\
\hline 2005 & 2,031 & 26.03 & 87.44 & 12.56 \\
2006 & 1,840 & 23.30 & 90.43 & 9.57 \\
2007 & 2,290 & 25.45 & 92.48 & 7.52 \\
Total & 6,161 & & & \\
\hline
\end{tabular}

* Include theses, dissertations, books, book chapters, texts downloaded from the internet, newspaper articles, URLs, legal references, among other documents. 
coauthored articles published in the JAOS, in addition to international authors, who account for $2.89 \%$ of the authorships

\section{Dental Research Fields}

Figure 2 presents a list of the dental research fields and correlated areas to which the articles published in the JAOS between 2005 and 2007 belonged. Overall, the articles pertained to four main areas: Endodontics, Restorative Dentistry, Dental Materials and Prosthodontics. Together, they represent almost $50 \%$ of the papers. However, it is important to stress the heterogeneous nature of the journal,

TABLE 5- The top 10 most cited scientific journals in the JAOS (2005-2007) and their Impact Factor (IF)

\begin{tabular}{|c|c|c|c|c|c|c|c|}
\hline \multicolumn{2}{|l|}{2005} & \multicolumn{2}{|l|}{2006} & \multicolumn{2}{|l|}{2007} & \multicolumn{2}{|l|}{ 2005-2007 } \\
\hline Journal & * & Journal & * & Journal & * & Journal & * \\
\hline J Dent Res (1.702) & 108 & J Endod (3.077) & 109 & J Prosthet Dent (0.879) & 118 & J Endod (3.077) & 310 \\
\hline J Endod (3.077) & 108 & J Prosthet Dent (0.879) & 100 & J Dent Res (3.475) & 94 & J Prosthet Dent (0.879) & 303 \\
\hline J Prosthet Dent (0.879) & 85 & J Dent Res (3.475) & 90 & J Endod (3.077) & 93 & J Dent Res (3.475) & 292 \\
\hline Dent Mater (2.381) & 84 & J Oral Rehabil (1.044) & 67 & Dent Mater (2.381) & 92 & Dent Mater (2.381) & 217 \\
\hline Caries Res (2.304) & 54 & Int Endod J (3.077) & 55 & Oper Dent (1.449) & 67 & J Oral Rehabil (1.044) & 167 \\
\hline J Oral Rehabil (1.044) & 45 & J Clin Periodontol (2.380) & 45 & J Dent (1.702) & 56 & Caries Res (2.304) & 142 \\
\hline J Dent (1.702) & 43 & Caries Res (2.304) & 45 & J Oral Rehabil (1.044) & 55 & J Dent (1.702) & 136 \\
\hline Am J Orthod Dentofacial & & Dent Mater (2.381) & 41 & Am J Dent (1.027) & 51 & Int Endod J (1.429) & 130 \\
\hline Orthop (0.968) & 36 & J Dent (1.702) & 37 & Am J Orthod Dento- & & Oper Dent (1.449) & 119 \\
\hline Am J Dent (1.027) & 34 & Quintessence Int (0.606) & 35 & facial Orthop (0.968) & 48 & Am J Dent (1.027) & 109 \\
\hline Int J Prosthodont (1.660) & 32 & & & Int Endod J (1.429) & 47 & & \\
\hline
\end{tabular}

*Number of citations of the journal. ( ) Impact Factor.

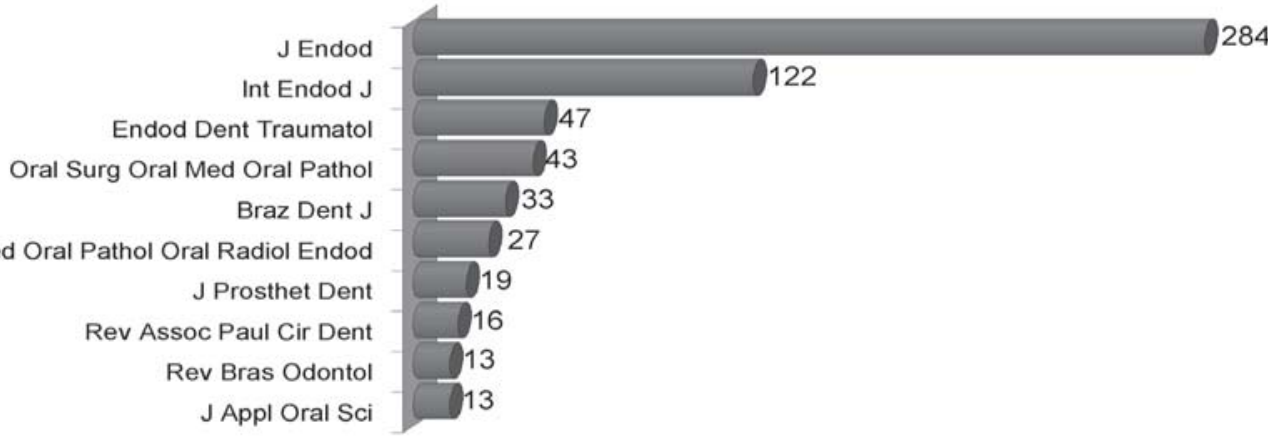

FIGURE 3- Journals of the area of Endodontics most frequently cited in the JAOS between 2005 and 2007

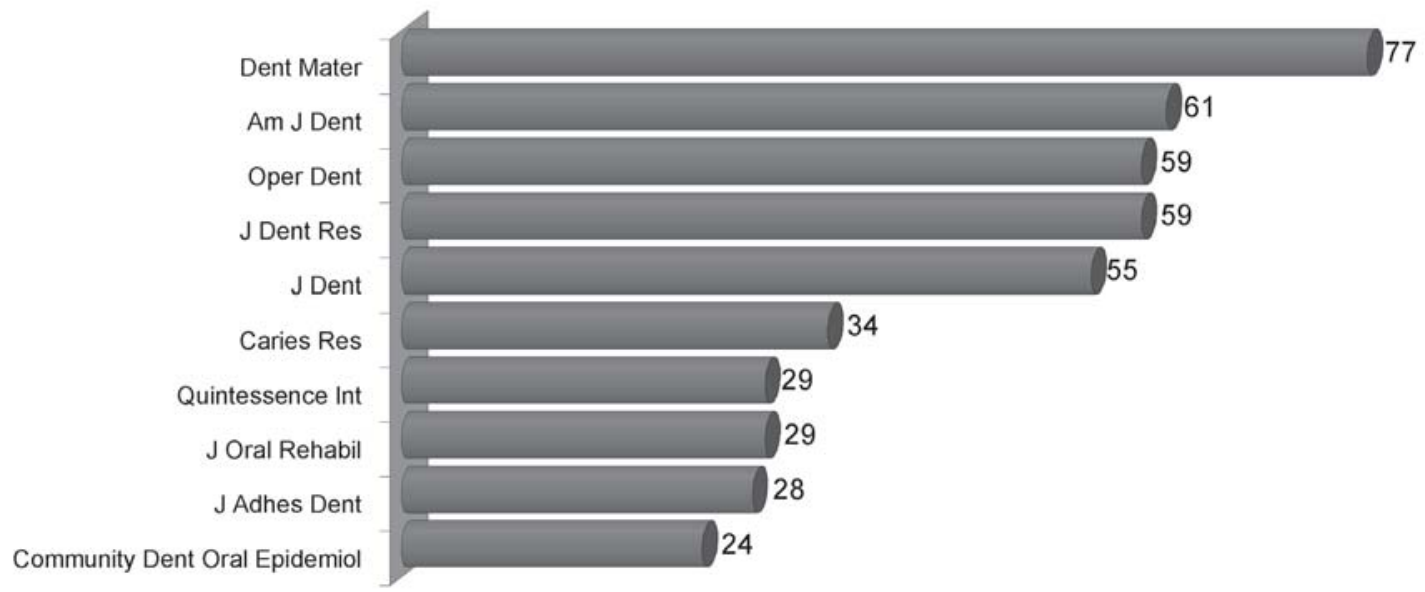

FIGURE 4- Journals of the area of Restorative Dentistry most frequently cited in the JAOS between 2005 and 2007 


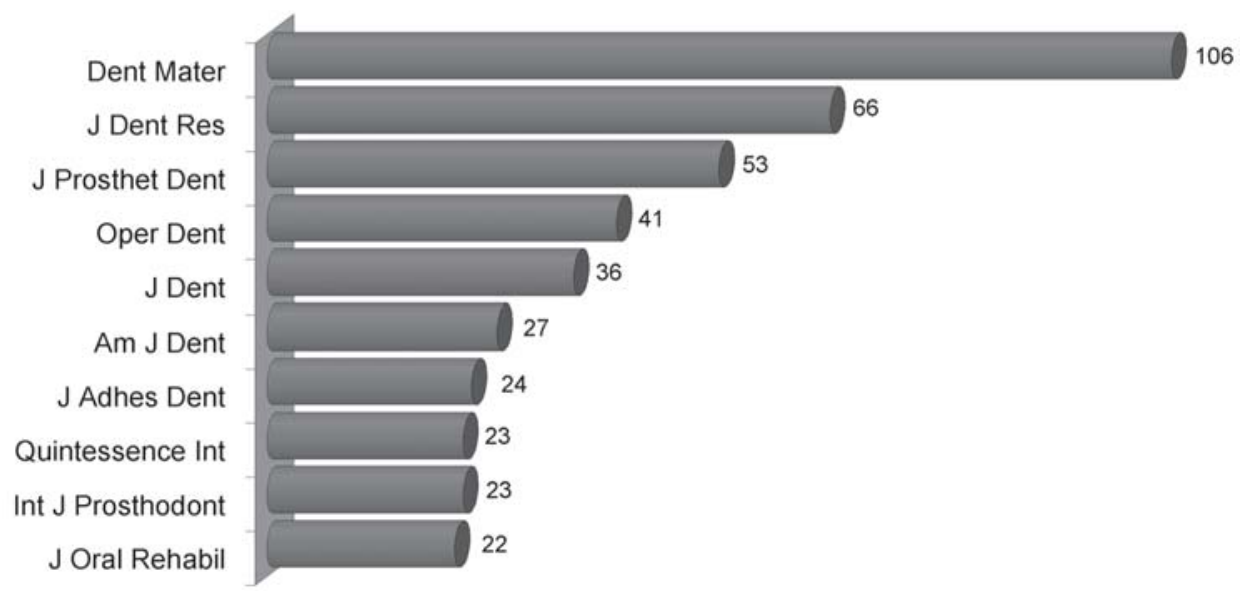

FIGURE 5- Journals of the area of Dental Materials most frequently cited in the JAOS between 2005 and 2007

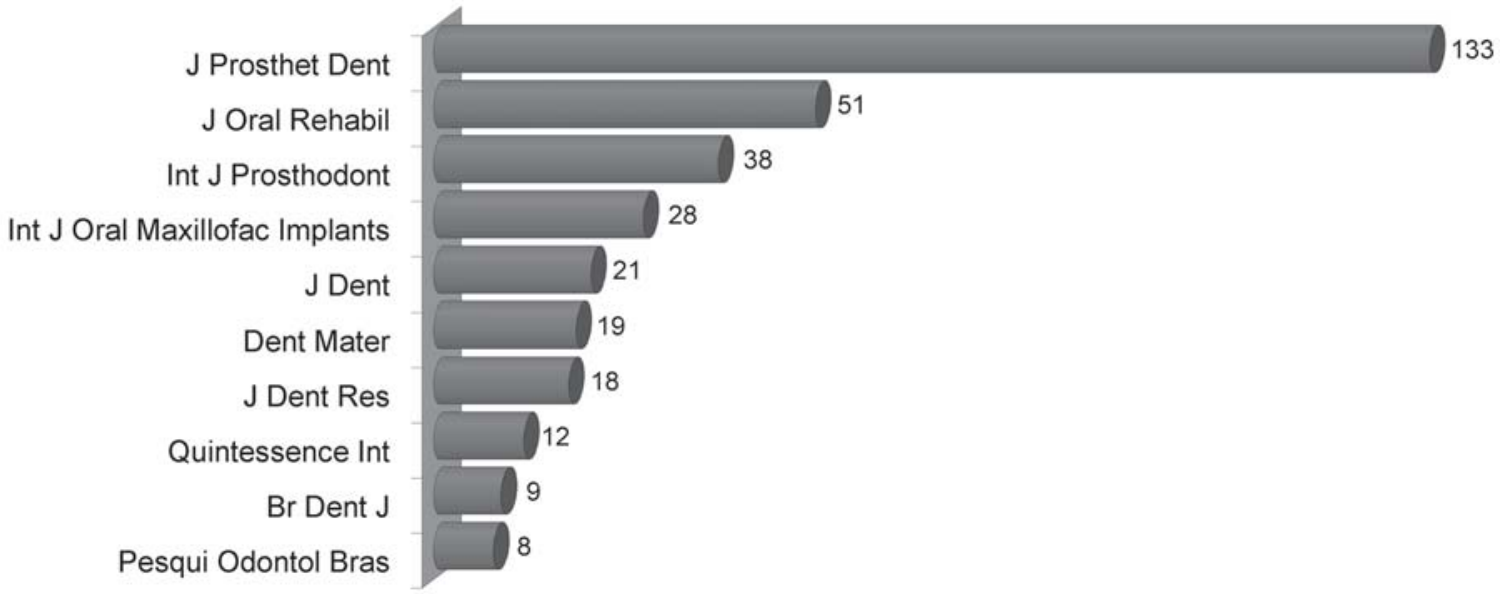

FIGURE 6- Journals of the area of Prosthodontics most frequently cited in the JAOS between 2005 and 2007

which accepts articles from areas such as Forensic Dentistry and Speech Pathology/Audiology.

Speech Pathology/Audiology articles with contents related to Dentistry are considered one of the highlights of the JAOS. As the Campus of Bauru of the University of São Paulo has a Speech Pathology/Audiology course, a considerable number of studies are developed involving a partnership approach between these areas, resulting in interesting and relevant original research articles.

\section{Sources of Information Cited as References in the Articles Published in the JAOS}

The review of the citations of full-text papers in the articles published in the JAOS in the 2005-2007 period shows that the majority of articles belong to journals indexed in international databases rated as International QUALIS A by CAPES and having a high Impact Factor in the dental area (Table 5).

As much as 6,161 references distributed in 247 published articles were reviewed. Among these references, $90 \%$ were articles published in scientific journals and the remaining $10 \%$ referred to other sources, like theses, dissertations, books, book chapters, internet-based texts, newspaper articles, URLs, legal references and others. The number of references cited per article was 26, 23 and 25 on the average, for the years 2005, 2006 and 2007, respectively (Table 4).

The most frequently cited scientific journals in the 2005 , 2006 and 2007 JAOS volumes were also identified (Table 5). Almost all journals are reputable scientific publications in dentistry and correlated areas, rated as International QUALIS A by CAPES. It is interesting to point out that the Journal of Dental Research, Journal of Endodontics and Journal of Prosthetic Dentistry alternated among the first three positions in the ranking of the most cited journals. The other journals listed in Table 4 were practically the same in the 3 -year period evaluated in this survey, only changing their positions in the ranking.

\section{Most Frequently Cited Journals per Area}

Figures 3-6 present the ranking of the most frequently cited journals in the articles published in the areas of Endodontics, Restorative Dentistry, Dental Materials and Prosthodontics, respectively. In the analyzed period, most articles published in the JAOS belonged to these areas, as shown in Figure 2.

The main source for Endodontics was the Journal of Endodontics, which corresponded to over twice the citations of other journals. The most cited journal in articles belonging 
to the areas of Dental Materials and Dentistry was Dental Materials. The articles of Prosthodontics cited mostly the Journal of Prosthetic Dentistry, which had a number of citations considerably larger than the second most cited journal in this area, Journal of Oral Rehabilitation. In Restorative Dentistry, the citation of journals was more balanced, comprehending Dental Materials, American Journal of Dentistry, Operative Dentistry, Journal of Dental Research and Journal of Dentistry, among others.

The Brazilian journals that appeared in the top-10 list of the most cited journals in the four areas mentioned above were the Brazilian Dental Journal, Revista da Associação Paulista dos Cirurgiões Dentistas, Revista Brasileira de Odontologia and Journal of Applied Oral Science, for articles of Endodontics, and the Pesquisa Odontológica Brasileira for articles of Prosthodontics, occupying the 10th position with 8 citations.

\section{CONCLUSIONS}

Based on a comprehensive bibliometric analysis of the articles published in the JAOS between 2005 and 2007, it may be concluded that:

- The number of submitted manuscripts remained the same, whereas the number of rejected manuscripts increased considerably;

- There was a predominance of original research articles, as expected, and the inclusion of a new category of article: case reports;

- The geographic distribution of the authors increased, covering almost all the Brazilian States, although the research centers responsible for the great part of scientific production remained the same;

- There was an interchange among Endodontics, Dentistry, Dental Materials and Prosthodontics, as the dental research fields with most representativeness;

- Full-text papers from scientific journals were the most cited references, corresponding to $87.44 \%, 90.43 \%$ and $92.48 \%$ of all bibliographic sources in the volumes published in 2005, 2006 and 2007, respectively.

- In its 16 years of history, the JAOS established itself as an important vehicle for dissemination of dental research, increasing considerably its visibility and accessibility to the national and international scientific community. The analysis of the data retrieved in this bibliometric analysis allowed evaluating the journal's current management strategies, and identifying important issues that will help outlining the future directions for the internationalization of this scientific dental publication.

\section{ACKNOWLEDGEMENTS}

Dr. Santos, the current Editor-in-Chief, would like to express all his respect and gratitude for the invaluable contribution of all the authors, reviewers and the former editors of the Revista da Faculdade de Odontologia de Bauru and the JAOS: Dr. Aguinaldo Campos Junior (1993-1995), Dr. Rumio Taga (1996-2000), Dr. José Mauro Granjeiro (2001-2004) and Dr. Ricardo Marins de Carvalho (20052006).

\section{REFERENCES}

1- Ferriols R, Santos B, Artacho S, Clopés A, Guerrero MD, Ordovás MJ, et al. A bibliometric analysis of the Farmácia Hospitalaria Journal (20012006). Farm Hosp. 2007;31(3)141-9.

2- Figueira I, Leta, Meis L. Avaliação da produção científica dos principais periódicos brasileiros de psiquiatria no período de 1981 a 1995. Rev Bras Psiquiatr. 1999;21(4):201-8.

3- J Appl Oral Sci. Bauru 2005;13.

4- J Appl Oral Sci. Bauru 2006;14.

5- J Appl Oral Sci. Bauru 2007;15.

6- Pincus HA, Henderson B, Blackwood D, Dial T. Trends in research in two general psychiatric journals in 1969-1990: research on research. Am J Psychiatry. 1993;150(1):135-42. 